\title{
A Study of the Level of Satisfaction with the Quality of Educational Services among Students of Nursing- Midwifery in Islamic Azad University of Dezful Based on the Model of European Foundation of Quality Management
}

\author{
Hagar Roshanaei ${ }^{1, \star}$, Faranak Omidian ${ }^{2}$, Ali Akbar Nazari ${ }^{2}$ \\ ${ }^{1}$ Department of Education, Gotvand Branch, Islamic Azad University, Gotvand, Iran \\ ${ }^{2}$ Department of Education, Dezful Branch, Islamic Azad University, Dezful, Iran \\ *E-mail address: r.roshanaee200@yahoo.com
}

\begin{abstract}
This study aimed to examine level of satisfaction with the quality of educational services among students of nursing-midwifery in Islamic Azad University of Dezful based on EFQM model. Statistical population of this survey consisted of all university students who had spent at least one semester in midwifery-nursing faculty of Islamic Azad university of Dezful. 270 students were selected through random sampling method. A questionnaire was developed by the researcher of current study based on customer-centered orientation of EFQM organizational excellence model. Data was analyzed through descriptive statistics and Chi-Square Test. The results showed that level of satisfaction at the educational services of nursing-midwifery and the affiliated hospitals was low $(p=0.99)$. Based on Freidman test, level of satisfaction at the accountability of staff was the most important factor, and it had the highest priority (mean rank 2/77). On the other hand, level of satisfaction at post-educational services was the least important, and it had the lowest priority (mean rank 2/30).
\end{abstract}

Keywords: students' satisfaction; midwifery-nursing faculty; EFQM organizational excellence model

\section{INTRODUCTION}

One of the most important criteria in the quality of work and its continuous improvement is to attract customers and to keep them. Higher education is one of the most important organizations whose aim is to educate people and to develop human resources. Higher education is the foundation of progress and development in every country. A sustainable development in higher education system involves improvement in both qualitative and quantitative aspects of this system.

The model of European Foundation for Quality Management (EFQM) is a multidimensional model which is based on nine criteria. Five criteria (leadership, strategy, people, 
partnership and resources, processes) are related to enablers. The other four factors (people results, customer results, society results, business results) are related to results.

The enablers' criteria indicate what the organization is doing and the results' criteria show what the organization has achieved. The results are obtained by enablers. Also, the results help us to improve the enablers. The excellent organization continuously measures the results related to their customers (Faraji et al, 2010).

The cost of attracting a new customer is five to 10 times more than retaining current the customer. Today, organizations are able to properly explore their customers' expectations and take the necessary measures to address those expectations. Business excellence models are tools for improving quality (Biekzad et al, 2009). The aim of this study was to examine level of satisfaction at the quality of educational services among students of nursing-midwifery in Islamic Azad University of Dezful based on the model of European Foundation for Quality Management.

\section{RESEARCH METHOD}

This research is a descriptive-survey study which is based on the data collected by a questionnaire. The statistical population consisted of all students of nursing and midwifery (first and second semester of 1390-91). This group totally consisted of 898 students. Among these students, 548 people were studying midwifery and 350 people were studying nursing. Samples were selected through stratified random sampling method based on Morgan table, 270 students were selected for the study. 160 participants were midwifery students and 110 participants were nursing students.

\section{INSTRUMENT (MATERIAL)}

The questionnaire was made by the researcher of the study on the basis of criteria related to customer in the model of European Foundation for Quality Management.

This questionnaire was modified on the basis of some experts' views.

\section{RELIABILITY AND VALIDITY OF THE SCALE}

\section{1. Validity}

In order to determine the validity of the questionnaire, the supervisor and advisor of the research were consulted. A number of questions were modified or removed from the questionnaire. Finally, 20 questions were included in the questionnaire.

\section{2. Reliability}

In order to determine the reliability of the questionnaire, Cronbach alpha coefficient was calculated. The obtained value for satisfaction questionnaire was 0.881 .

Since this value is larger than 0.7 , the rest of the research could be conducted by a larger sample of population (see Table 1). 
Table 1. The reliability coefficients.

\begin{tabular}{|c|c|c|}
\hline \multicolumn{2}{|c|}{ Reliability coefficients } & Statistical Indicator \\
\hline Bisection & Cronbach's alpha & Scale \\
\hline $0 / 616$ & $0 / 881$ & Student satisfaction \\
\hline $0 / 706$ & $0 / 713$ & $\begin{array}{c}\text { Satisfaction at the quality of } \\
\text { communication }\end{array}$ \\
\hline $0 / 687$ & $0 / 780$ & $\begin{array}{c}\text { Satisfaction at the quality of follow-up } \\
\text { educational services }\end{array}$ \\
\hline $0 / 530$ & $0 / 679$ & $\begin{array}{c}\text { Satisfaction at the quality of educational } \\
\text { services }\end{array}$ \\
\hline $0 / 342$ & $0 / 406$ & $\begin{array}{c}\text { Satisfaction at the quality of staff } \\
\text { accountability }\end{array}$ \\
\hline
\end{tabular}

\section{METHODS OF DATA ANALYSIS}

1. Descriptive statistical methods which included frequency table, percentages, diagrams, mean, and standard deviation

2. Inferential statistical methods which included Freidman test, Chi-square test for goodness of fit, Leuven test, independent $\mathrm{T}$ test, multi-variable analysis of variance (MANOVA), analysis of variance (ANOVA), and Duncan's test.

SPSS software was used to analyze the data. For all hypotheses, level of significance was 0.05 .

\section{RESULTS}

The descriptive results showed that midwifery students had the highest frequency (160 people or $59.3 \%$ ) and nursing students had lowest frequency (110 people or $40.7 \%$ ) in the sample.

The second-year students had the highest frequency (151 people or $55.9 \%)$ and the fourth-year students had the lowest frequency (29 people or 10.7\%) in the sample of study.

Based on the frequency distribution and the percentage of general research question, the low-satisfaction at the performance of midwifery-nursing faculty had the highest frequency (149 people or $55.2 \%$ ) and the high-satisfaction at the performance of midwifery-nursing faculty had the lowest frequency (5 people or 1.9\%) (Table 2 and Diagram 1). 
Table 2. Level of students' satisfaction at the performance of nursing-midwifery faculty in Islamic Azad University of Dezful and the affiliated hospitals.

\begin{tabular}{|c|c|c|c|}
\hline Frequency & Frequency & \multicolumn{2}{|c|}{} \\
\hline 55.2 & 149 & Low & \\
43.0 & 116 & The average & $\begin{array}{c}\text { The general } \\
\text { question }\end{array}$ \\
1.9 & 5 & High & \\
\hline 100.0 & 270 & Total & \\
\hline
\end{tabular}

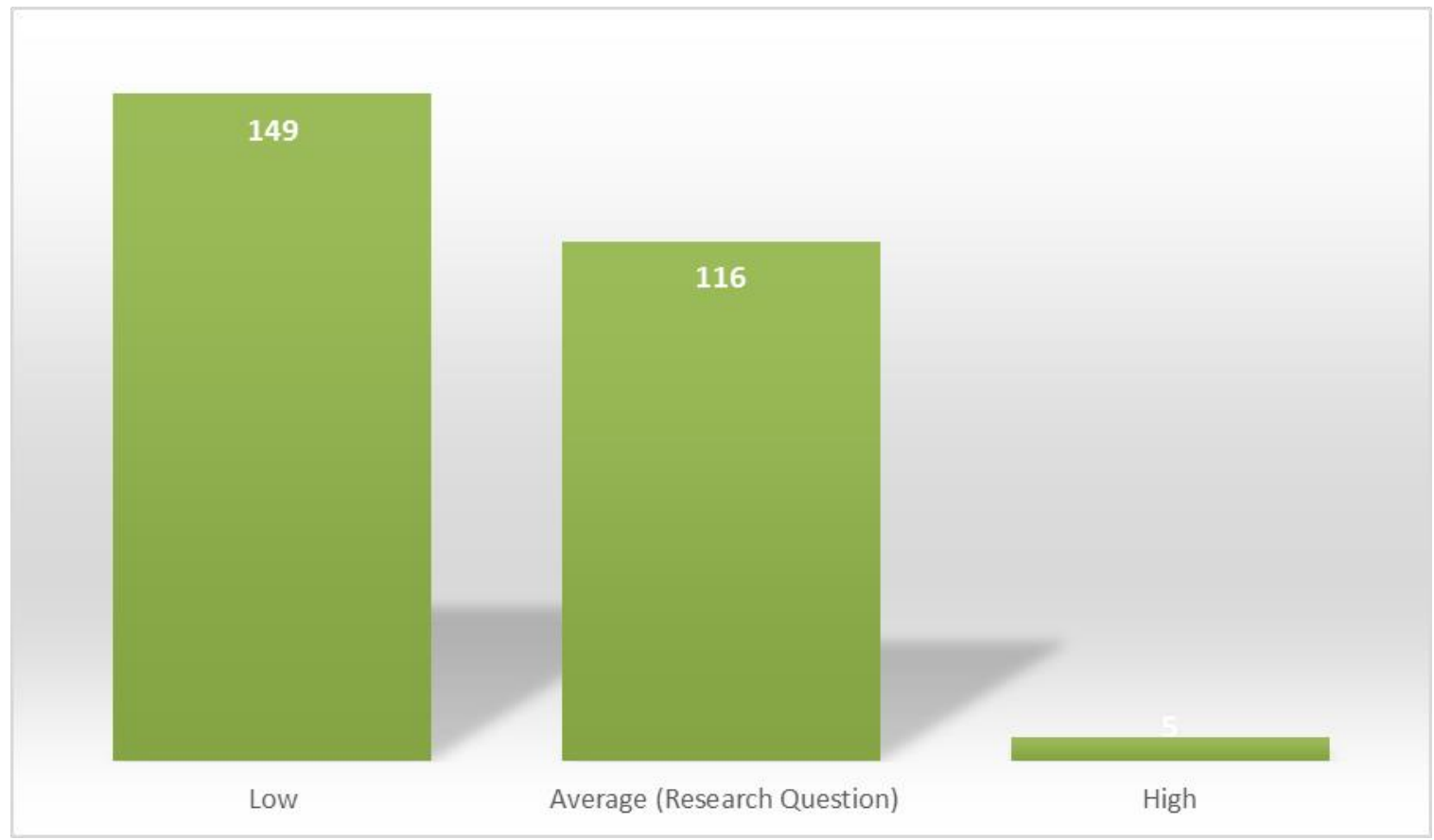

Diagram 1. Frequency distribution for the general research question.

The mean and standard deviation of students' satisfaction scores were 2.89 and 0.84 respectively. The obtained mean is lower than the mean of Likert scale (the range was from 1 to 5; so, the mean of Likert scale was 3). It shows that students' satisfaction is low.

Mean and standard deviation of students' satisfaction scores at quality of communication were 2.84 and 0.74 respectively. Also, Mean and standard deviation of students' satisfaction scores at follow-up educational services were 2.70 and 0.78 respectively. It shows a low level of satisfaction among students.

Mean and standard deviation of students' satisfaction scores at quality of educational services were 2.97 and 0.44 respectively. Mean and standard deviation of students' 
satisfaction scores at quality of staff accountability were 2.99 and 0.37 respectively. It shows a medium level of satisfaction among students.

Based on Freidman test, satisfaction at the quality of staff accountability had the highest priority (with a mean rank of 2/77) and the level of satisfaction at follow-up educational services had the lowest priority (with a mean rank of 2/30) among the factors related to students' satisfaction.

\section{DISCUSSION AND CONCLUSION}

The mean of students' satisfaction scores at the performance of midwifery-nursing faculty was 2.89 out of 5 . It shows a low satisfaction. These results are not consistent with the results obtained from EFQM model for customers. Najmi (2010) says that the only way to satisfy customers is to focus on their demands and expectations.

The results of this study are consistent with the results obtained by Banidavoodi et al (2011). On the other hand, they are not consistent with the results of the study conducted by Aslani Katooli (2012). To explain these findings, we can say that the main reason of students' dissatisfaction is related to enablers' factors.

\section{Quality of communication}

On the basis of Liker scale, the mean of students' satisfaction scores is 2.84 out of 5 . It shows the quality of communication in the faculty. These results are consistent with the results obtained by Banidavoodi et al (2011). However, they are not consistent with the results of studies conducted by Akhshik and Farajpahlou (2009), Ezadi et al (2010), and Faraji et al (2010). In the below table, the weaknesses of faculty and some suggested solutions have been presented.

Table 3. The weaknesses of communication system in the faculty of nursing-Midwifery and some suggested solutions.

\begin{tabular}{|c|c|}
\hline \multicolumn{2}{|c|}{ Quality of Communications } \\
\hline Suggested solution & Weaknesses \\
\hline $\begin{array}{c}\text { Allocation of a certain time to students to } \\
\text { have access to lecturers, head of department, } \\
\text { and clinical trainers }\end{array}$ & $\begin{array}{c}\text { Dissatisfaction at inaccessibility to lecturers, } \\
\text { head of department, and clinical trainers }\end{array}$ \\
\hline $\begin{array}{c}\text { Creating conditions for students to have } \\
\text { access to internet in educational places }\end{array}$ & $\begin{array}{c}\text { Students' dissatisfaction at communication } \\
\text { and information system }\end{array}$ \\
\hline $\begin{array}{c}\text { Holding educational courses for staff to teach } \\
\text { them how to offer services to customers and } \\
\text { how to have effective relation with them }\end{array}$ & $\begin{array}{c}\text { Students' dissatisfaction at staff for not } \\
\text { having effective relations }\end{array}$ \\
\hline
\end{tabular}

\section{The quality of follow-up educational services}

The mean score at the quality of follow-up educational services was 2.70 . It shows a low level of satisfaction. The results related to this index are consistent with the results obtained by Ezadi et al (2009). On the other hand, these results are not consistent with the results of a study conducted by Akhshik and Farajpahlou (2009). 
In the following table, the weaknesses related to follow-up educational services and the suggested solutions have been presented.

Table 4. The weaknesses related to follow-up educational services in the faculty and affiliated hospitals, and the suggested solutions have been presented.

\begin{tabular}{|c|c|}
\hline \multicolumn{2}{|c|}{ The quality of follow-up educational services } \\
\hline Suggested solution & Weaknesses \\
\hline $\begin{array}{c}\text { Holding workshops on the importance of } \\
\text { having an effective relationship and to teach } \\
\text { them how to offer services to customers } \\
\text { (students) }\end{array}$ & $\begin{array}{c}\text { Dissatisfaction at non-accountability and non- } \\
\text { responsibility to address educational } \\
\text { problems }\end{array}$ \\
\hline $\begin{array}{c}\text { Holding workshops on the importance of } \\
\text { having an effective relationship and to teach } \\
\text { them how to offer services to customers } \\
\text { (students) }\end{array}$ & $\begin{array}{c}\text { Dissatisfaction at the ways that educational } \\
\text { services are offered }\end{array}$ \\
\hline $\begin{array}{c}\text { Designing a proper plan for the evaluation of } \\
\text { activities }\end{array}$ & $\begin{array}{c}\text { Lack of a clearly-defined plan for the } \\
\text { evaluation of activities }\end{array}$ \\
\hline
\end{tabular}

\section{Quality of educational services}

The results related to this index are consistent with the results obtained by Aslani Katooli (2012) and Ezadi et al (2009). However, they are not consistent with the results of the study conducted by Faraji et al (2010).

Therefore, it can be said that students' satisfaction at the quality of library resources, practical trainings in hospitals, educational methods employed by the lecturers, and equipments and facilities in the faculty and hospitals is medium. It shows that nursingmidwifery faculty is improving its quality management. But, because the mean score of satisfaction is not high, more emphasis should be placed on the new theories of quality management. Also, authorities and educational planners should attempt to improve the performance of systems in these areas.

\section{Accountability of staff}

In this study, among the various indices, accountability of staff had the highest mean. These results are not consistent with the results of the study conducted by Kebriaie et al (2005) in which accountability of staff had the minimum mean score.

Therefore, it can be said that students have a medium level of satisfaction at the accountability of clinical trainers, the presence of faculty member in the department, and the ability of faculty to offer suitable services. This shows that faculty of nursing-midwifery is moving toward new theories of quality management. But, because the mean score of satisfaction is not high, more emphasis should be placed on the new theories of quality management. Also, authorities and educational planners should attempt to improve the performance of systems in these areas. 


\section{References}

[1] Akhshik S., Farajpahloo A. (2009). Organizational excellence model and quality of information technology management in the libraries of medical sciences: A case study in the University of JundiShappor Medical Sciences. Health Information Management, 7(2): 21 -33.

[2] Banidavoodi Sh., Mehr Alizadeh Y., Parsa A. (2011). A study of education quality in medical faculties in educational hospitals of Ahwaz based on the model of European Foundation for Quality Management (EFQM). MA thesis. Shahid Chamran University of Ahwaz.

[3] Beighzad J., Behboudi A. (2009). A study of customer-centered orientation on the basis of EFQM organizational excellence model. Quarterly of industrial management of Islamic Azad University of Sanandaj, 9(4): 111- 120.

[4] Faraji A., Ramazani A., Azizi Fadafan M. (2010). A study of satisfaction level among students of Zabol Medical Sciences University on the basis of customers' results in the model of European Foundation for Quality Management (EFQM). Rostameyeh Scientificresearch Quarterly 3. Zabol Medical Sciences University.

[5] Kebriaie A., Roodbari M. (2005). The gaps in the quality of services in Zahedan Medical Sciences University: Students' views about the current conditions and ideal conditions. The Iranian Journal of Medical Sciences Education, 5(1): 53-61.

[6] Najmi M. (2010). EFQM excellence award model. Tehran: Saramad Publications.

[7] Aslanikatooli S., Abdollahi A., Taghavi A. (2012). Surveying the postgraduate students' satisfaction regarding customer results criteria model EFQM. Empirical Observations in Iran. Research Journal of International studies. 